\title{
Effect of Weight Bearing and Non-Weight Bearing Aerobics Combined with Resistance Exercises on the Cardiopulmonary Functions of Nigerians with Type 2 Diabetes Mellitus
}

\author{
Osho Oluwaseyi Abigail ${ }^{*}$, Akinbo Sunday ${ }^{1}$, Osinubi Abraham ${ }^{2}$ and Olawale Olajide ${ }^{1}$ \\ ${ }^{1}$ Department of Physiotherapy, College of Medicine, University of Lagos, Lagos, Nigeria \\ ${ }^{2}$ Reproductive Endocrinology unit, Department of Anatomy, College of Medicine, University of Lagos, Lagos, Nigeria
}

\begin{abstract}
Background: Nigerians with type 2 diabetes (T2DM) often develop cardiopulmonary complications which necessitates prescription of therapeutic exercises. Progress monitoring post exercise prescription in the management cardiopulmonary complications is paramount.

Objective: This study was designed to evaluate the effect of weight bearing aerobics combined with resistance exercises (WBARE) and non-weight bearing aerobic combined with resistance exercises (NWBARE) on selected cardiopulmonary parameters of Nigerians with T2DM. It also assessed the changes in these parameters at specified duration in the intervention period.
\end{abstract}

Method: A total of 60 subjects ( 36 females and 24 males) within the age range of $40-75 y$ years were consecutively recruited and randomly assigned into the 12 weeks supervised WBARE (20) or NWBARE (20) or a control group (20). Pre- and post-outcome measures which included cardiopulmonary parameters; resting arterial systolic and diastolic blood pressure (RASBP and RADBP), resting rate pressure product (RRPP), oxygen uptake ( $\mathrm{VO}_{2}$ max), forced vital capacity (FVC) and forced expiratory volume in one second $\left(F E V_{1}\right)$ were assessed at baseline and at the end of 4 th, 8th and 12th week. Glycosylated haemoglobin level ( $\mathrm{HbA1c}$ ) was assessed at baseline and at the end of 12th week. Data were analyzed using descriptive and inferential statistics. Level of significant was set at $p<0.05$

Results: RASBP, RADBP, RRPP and HbA1c were significantly decreased in WBARE and NWBARE groups ( $p=$ $<0.05) . \mathrm{VO}_{2} \max$ and $\mathrm{FEV}_{1}$ were also significantly increased in both groups $(p<0.05)$. WBARE recorded significant improvement in FEV and FVC values than NWBARE group when compared with control $(p<0.05)$. Significant improvement in RRPP, $\mathrm{VO}_{2}$ max and $\mathrm{FEV}_{1}$ occurred as early as four weeks post intervention between the groups.

Conclusion: WBARE and NWBARE improved cardiopulmonary functions in Nigerian adults with T2DM. WBARE may be more effective in the management of pulmonary functions. Assessment of patients post intervention should commence as early as four week.

Keywords: Aerobic exercise; Resistance exercise; Cardiopulmonary; Glycosylated hemoglobin; Type 2 diabetes

\section{Introduction}

Diabetes mellitus (DM) is a global health problem predisposing to markedly increased morbidity and mortality [1]. In Nigeria, the national prevalence of DM was estimated to be $6.8 \%$ in adult older than 40 years [2]. Crude prevalence rates of 7.7 and $5.7 \%$ were estimated for males and females in Port Harcourt, southern part of Nigeria [3]. A study of the prevalence of DM in Nigeria showed that T2DM is the most common type of DM accounting for about $90 \%$ of cases $[4,5]$. Sixty two percent of persons with T2DM in the northern part of Nigeria were estimated to be hypertensive [6]. In 2004, heart disease was noted on 68 percent of DM-related death among people aged 65 years or older [5].

The association of reduced lung function and DM has been described among Nigerians with T2DM, although the clinical significance of this association is not known [7]. Possible links between respiratory impairment in people with DM have been attributable to increased body mass index (BMI), subsequent loss of respiratory compliance, neuropathies, loss of strength of the respiratory muscles, and other confounding variables [8]. Reduced lung volumes and airflow limitation have also been reported to be chronic complications of T2DM [8]. Furthermore, microvascular complications and reduced ventilatory function of the lungs have been linked to poor glucose control [9].
Therapeutic exercise has been shown to be a valuable and economical therapeutic modality that may be considered as a beneficial adjunct for DM especially the T2DM [10-11]. Regular physical exercise of moderate intensity had been reported to be effective in the prevention and delay of onset of T2DM [12]. It has been proven to increase insulin sensitivity and ameliorate glucose and lipid metabolism in people with DM $[13,14]$. A combination of aerobics and resistance exercises have been established to be of greater beneficial adjunct for improvement of glycaemia in T2DM patients than either aerobics or resistance exercise alone [11]. However, no structured exercise programme, specific effect of exercise modes and specified time frame for assessment of improvement post exercise prescription is yet in place for people with T2DM in Nigerian population [15].

*Corresponding author: Osho Oluwaseyi Abigail, Department of Physiotherapy, Faculty of Clinical Sciences, College of Medicine, University of Lagos, Lagos, Nigeria, Tel: +1 587899 1404; E-mail: oaosho@cmul.edu.ng

Received November 05, 2011; Accepted December 17, 2011; Published December 23, 2011

Citation: Osho OA, Akinbo S, Osinubi A, Olawale O (2011) Effect of Weight Bearing and Non-Weight Bearing Aerobics Combined with Resistance Exercises on the Cardiopulmonary Functions of Nigerians with Type 2 Diabetes Mellitus. Diabetes Metab S10:001. doi:10.4172/2155-6156.S10-001

Copyright: @ 2011 Osho OA, et al. This is an open-access article distributed under the terms of the Creative Commons Attribution License, which permits unrestricted use, distribution, and reproduction in any medium, provided the original author and source are credited. 
Citation: Osho OA, Akinbo S, Osinubi A, Olawale O (2011) Effect of Weight Bearing and Non-Weight Bearing Aerobics Combined with Resistance Exercises on the Cardiopulmonary Functions of Nigerians with Type 2 Diabetes Mellitus. J Diabetes Metab S10:001. doi:10.4172/21556156.S10-001

Page 2 of 7

People with T2DM often develops foot pathologies [16] which necessitates the prescription of non-weight bearing aerobic exercise (NWABE) as against weight bearing aerobic exercise (WBAE) they regularly engage in [18]. Although the prescription of NWBAE may be informed by the assumption that WBAE may aggravate existing foot pathologies, there is no established evidence on NWBAE benefit compared to WBAE especially on the cardiopulmonary functions of the Nigerians with T2DM in which cardiopulmonary complications is a major issue of concern in people with T2DM. Bicycle ergometer is usually the modality of choice for non-weight bearing exercise [19]. Treadmill however, simulate walking which is a weight bearing exercise performed on day to day activities [20]. Inclination of this modality at a gradient of $1 \%$ had been established to give similar energy cost with outdoor walking as this gradient compensate for air resistance that will usually be present outdoor [20]. The American Sport Medicine Association and American Diabetes Association have recommendation aerobics and resistance exercises for people with diabetes [21], however, studies on the therapeutic effects of various exercise modes such as weight bearing aerobics on treadmill and non-weight bearing aerobic on bicycle ergometer when combined with the recommended resistance exercises on the cardiopulmonary and glucose control parameters of people with T2DM are sparsely reported especially in Nigerian population $[21,22]$. This study was thus designed to investigate the cardiopulmonary, glucose control and anthropometric responses of individuals with T2DM to therapeutic exercises such as weight bearing and non-weight bearing aerobics when combined with resistance exercises. It also investigated changes in variables at specified duration in the intervention period.

\section{Materials and Methods}

\section{Participants}

A total of 60 participants with T2DM (36 females and 24 males) within the age range of 40-75years participated in this randomized control study. The sample size for the study was calculated using the formula for comparative research studies based on the results of previous pilot study done before this study. The statistical power was at $80 \%$ while the desired significance criterion was 0.05 . The participants were consecutively recruited from the endocrinology unit of the Department of Medicine, Lagos University Teaching Hospital (LUTH), Idi-Araba, Lagos, Nigeria and Lagos State University Teaching Hospital (LASUTH), Ikeja, Lagos, Nigeria. They were screened for eligibility based on the inclusion criteria that, they had established T2DM (not less than duration one year), sedentary life style [score below 3 on the Rapid Assessment of Physical Activity Questionnaire, (RAPA) [23], no resistance exercises in the preceding 6 months and not on current insulin therapy. They were non-smoker, non-alcoholic with no physical restriction in terms of mobility and no pre-existing pulmonary infection or deformity of the trunk. Patients with severe complications of DM such as neuropathy, nephropathy, and retinopathy were also excluded from the study. Participants were randomly assigned to two exercise groups and a control group by a systematic random method. Each group comprised of twenty individuals with T2DM.The exercise groups included WBARE Group which comprised of participants who performed weight bearing aerobic exercises on treadmill combined with resistance exercises. NWBARE group were participants whose interventions were non-weight bearing aerobic exercises on bicycle ergometer combined with resistance exercises. Control group were subjects who did not undergo exercise intervention, but who participated in educational sessions only as also given to all participants who participated in the study.
All participants gave their written informed consent to participate in this study. Ethical approvals were obtained from the Research and Ethics Committee of the LUTH and LASUTH and the study was conducted between January 2010 to March 2011.

\section{Intervention}

The exercise protocols for this study were adopted validated exercise protocols from previous studies; Treadmill protocol at $1 \%$ gradient $[20,25]$ bicycle ergometer protocol at a load of 40 watt and a revolution of $60 \mathrm{rpm}[18,26]$ and one repetition maximum (1RM) for resistance exercise intensity assessment using free weights [25].

\section{Exercise protocols}

Warm up exercises: All subjects in both exercise groups (WBARE and NWBARE groups) performed ten minutes warm up exercise before the main aerobic exercise sessions, this constituted flexibility exercises, which involved range of motion exercise to all joints of the upper and lower limb and trunk.

Aerobics exercises for exercise groups: Subjects in WBARE group were required to walk on treadmill at a speed of $1.5 \mathrm{~km} / \mathrm{hr}$ and at a gradient of $0 \%$ in order to get accustom with the treadmill [27], progression was then made to a gradient of $1 \%$ which had been established from previous studies to correlate with outdoor walking and to compensate for the lack of air resistance in the research ground $[20,24]$. The speed of the treadmill was gradually increased to $3 \mathrm{~km} / \mathrm{hr}$ and thereafter increased by $1 \mathrm{~km} / \mathrm{hr}$ every two minutes.

Participants in the NWBARE group were required to exercise on bicycle ergometer, when sited on the bicycle ergometer, participants achieved free pedaling at a work load of 0 watts until they have established regular and steady pedaling rate $[18,26]$. The workload was then gradually increased to 40 watts [26] while the pedaling frequency was also gradually increased to 60 revolutions per minutes (rpm) [26,27]. Participants in both exercise groups were encouraged to exercise within moderate intensity range of $60-80 \%$ based on their predicted heart rate reserve [21]. The glucose level of the participants was checked using glucometer before and after exercise training as safety precaution against hypoglycemia, Borg's rate of perceived exertion was also used to also monitor the exercise intensity. Duration of aerobic exercise was 20 minutes, progression was such that participants exercise at $60 \%$ of their heart rate reserve from the baseline to the 4 th week, thereafter progressed to $70 \%$ from 5 th to 8 th week and $80 \%$ from 9 th to 12 th week. This was done to allow for gradually adaptation to the moderate intensity training. The aerobic exercises were performed thrice per week with no more than 2 consecutive days without aerobic exercise. The total aerobic sessions was 36 for the 12 weeks of the study.

Cool down exercises: Another 5 minutes for cool down was observed by the participants as they perform active full range of motion exercises of all joints of their upper limbs, lower limbs and trunk after the aerobic exercises. They thereafter rested for about ten minutes before commencing resistance exercises [18].

Resistance exercises: Resistance exercises of the muscle groups were done by participants in WBARE and NWBARE groups using dump bells and sand bags of known weights at each exercise session. The resistance regimen was done for flexors and extensors of the knees and elbows. Weights of different sizes which depended on the one repetition maximum (1-RM) of the muscle groups were considered suitable for the resistance exercises. Three sets were considered for each muscle group strengthened [25,27]. The participants also carried 
Citation: Osho OA, Akinbo S, Osinubi A, Olawale O (2011) Effect of Weight Bearing and Non-Weight Bearing Aerobics Combined with Resistance Exercises on the Cardiopulmonary Functions of Nigerians with Type 2 Diabetes Mellitus. J Diabetes Metab S10:001. doi:10.4172/21556156.S10-001

out strengthening exercises for both hands using tennis balls. They were encouraged to squeeze the ball as strongly as they could [25], making twelve repetitions per set. A set of twelve repetitions of the abdominal curl ups, back extension and bilateral straight leg raisings were also carried out by the participants at speeds comfortable to them [25]. Moderate intensity resistance range of $50 \%-70 \%$ of $1-\mathrm{RM}$ was considered [27]. This was determined for flexors and extensors of the knees and elbows. They started with $50 \%$ of 1 -RM from week 0 to 4 . They thereafter progressed to $60 \%$ of 1 -RM from week 5 to 8 of the study period and finally $70 \%$ of $1-\mathrm{RM}$ from week 9 to 12 [27]. Each session lasted for a total duration of about thirty three minutes including one minute recovery period [28]. Each set of resistance exercise lasted for about $25-30$ seconds [28].

Educational counseling session: The two experimental groups including the control groups had group educational counseling sessions at different times and fortnightly. This was done before commencement of the study and on the last days of the second, fourth, eighth, tenth and twelfth week. However, the contents of the educational counseling were the same for all the groups. Topics considered during the education session included; blood glucose monitoring and record keeping, recognition and management of hypoglycaemia and hyperglycaemia, medication adjustment based on nutrition and activity schedules, weight control and diet modification including meal plan, DM complications and importance of DM control.

\section{Control Group}

Subjects in this group had no exercise intervention. However, they participated in the group educational counseling which all other participants in the exercise groups participated in. The counseling was also targeted at reducing the attrition rate in the control group. Monthly rapid assessment of the physical activity levels of the participants in the control group was also done in order to monitor their physical activity level and to also ensure that they have not being engaging in exercises.

\section{Data Collection}

The instruments utilized for this study were; Treadmill machine (Daily Youth, England), bicycle ergometer (ergofit 200, German), weights, sandbags of different sizes in kilograms and Accucheck active glucometer and glucometer strips for blood glucose monitoring. The instuments utilized for data collection were medical microsoft spirometer (Schiller, Switzerland), mercury sphygmanometer (Baumanometer Desk Top model no. 320; W.A. Baum Co., Copiague, NY), stethoscope, combined weighing scale and height meter (Seradon, England), Tape rule calibrated in centimeter and inches, rapid assessment of physical activity level questionnaire (RAPA) [16,24], and NycoCard HbAlc reader II, Axis Shield PoC required for HbA1c analysis. These procedures for measuring with these instruments were according to validated protocols from previous studies [21,29-33]. These validity and reliability of these procedures had been ascertained and calibrations of these instruments were followed according to these protocols observed from previous studies [21,29-33].

Socio-demographic data of all participants were obtained at baseline; this included the age at last birthday, gender and duration of DM. All other outcome measures for this study which included cardiopulmonary and anthropometric variables were assessed at baseline and at the end of the 4th, 8th and 12th week. The glycosylated haemoglobin (HbAlc) was assessed at baseline and at the end of the 12 th week intervention period.

\section{Cardiopulmonary parameters}

Resting arterial blood pressures [systolic (RSBP) and diastolic (RDBP) were obtained using mercury shygmanometer and stethoscope. The unit of measurement was $\mathrm{mmHg}$. A mercury column sphygmomanometer (Baumanometer Desk Top model no. 320; W.A. Baum Co., Copiague, NY) was used to measure blood pressure. Subjects were required to be seated quietly for 20 minutes before measurements were taken according to the standardized methods recommended by the American Heart Association. The average of two systolic and diastolic blood pressure measures was recorded for data entry and analysis.

Resting rate pressure product (RRPP) was the product of resting arterial systolic blood pressure in $\mathrm{mmHg}$ and resting heart rate in beats per minutes, measured using the stethoscope placed at the apex of the heart at the 5th intercostal space, mid clavicular line [29].

Oxygen uptake $\left(\mathrm{VO}_{2}\right.$ max) for the participants was obtained using Rockport one mile walk test which had been found to be reliable and valid $[30,31]$. The subjects were required to walk for a mile as fast as they can on a track. The time taken to complete the one mile walk will be recorded and the heart rate is immediately recorded on finishing the walk. The age, gender and age of the subjects will also be documented.

The $\mathrm{VO}_{2} \max$ of the subject is then calculated using the formula;

$132.853-(0.0769 \times \mathrm{x})-(0.3877 \times \mathrm{x}$ Age $)+(6.315 \times$ Gender $)-(3.2649$ x T) - (0.1565 x HR) [30,31]

Where, $\mathrm{W}=$ Weight is in pounds (lbs), Gender Male=1 and Female $=0, T=$ Time, expressed in minutes and 100th of the minutes, $\mathrm{HR}=$ Heart rate is in beats per minutes and Age is in years.

The force vital capacity and the forced expiratory volume in one second were obtained using spirometer. The FEV and FVC were obtained using hand held medical spirometer. These pulmonary function tests were done for each subject at a consistent time of the day. The precise technique in executing various lung function tests for the present study was based on the operating manual of the instrument with reference to the official statement of the American Thoracic Society of Standardization of Spirometry [34]. Subjects were trained about the entire maneuver, and were encouraged to practice this maneuver before doing the pulmonary function tests. The parameters measured included force vital capacity (FVC) and force expiratory volume in 1 second $\left(\mathrm{FEV}_{1}\right)$.The tests were performed with each subject in the standing position. It was repeated three times after adequate rest. The average value was obtained and recorded. Subjects were asked to fully expire their lung gases into the spirometer after maximal inspiration. Values obtain from the maximal expiration included FEV $\mathrm{F}_{1}$ and FVC.

- FVC was the maximum amount of air that was expired after the maximum inspiration; it was reported in litres.

- $\mathrm{FEV}_{1}$ was the volume of air expired in the first second after a maximal inspiration. It was also recorded in litres

\section{Biochemical}

\section{- Glycosylated Haemoglobin Level (HbA1c)}

Subjects were required to fast for 12 hours before resting blood samples were collected from the antecubital vein [13] using standard venipuncture methods. HbAlc was analyzed using NycoCard HbAlc test (NycoCard reader II, Axis Sheild PoC, made in Norway). 
Citation: Osho OA, Akinbo S, Osinubi A, Olawale O (2011) Effect of Weight Bearing and Non-Weight Bearing Aerobics Combined with Resistance Exercises on the Cardiopulmonary Functions of Nigerians with Type 2 Diabetes Mellitus. J Diabetes Metab S10:001. doi:10.4172/21556156.S10-001

Page 4 of 7

\section{Statistical analysis}

Analysis of the descriptive characteristics of participants was done using descriptive and inferential statistics. The individual variables were evaluated to determine the changes in the three groups (WBARE, NWBARE and control) during the different periods (baseline, $4^{\text {th }}$ week, $8^{\text {th }}$ week and $12^{\text {th }}$ week). To investigate the effects of a variable within a group; the Within - Subjects factors analysis was utilized and the effects between the groups; Between - Subjects analysis were used according to Two Way ANOVA with a 95\% confidence interval. Two Way ANOVA was applied to detect differences among groups (WBARE, NWBARE and control). The Tukey's Honestly Significant Difference (Tukey HSD, available in SPSS was used for post-hoc comparison. Level of significance was set at $\mathrm{p}<0.05$.

\section{Results}

Table 1 shows the descriptive characteristics of the participants in
WBARE, NWBARE and control groups; the gender, age, duration of $\mathrm{DM}$, weight and height of the subjects were similar at baseline.

Tables 2 and 3 shows the within group comparison of the cardiopulmonary and glucose control parameters of WBARE and NWARE groups respectively at baseline, $4^{\text {th }}, 8^{\text {th }}$ and $12^{\text {th }}$ week.

Table 4 shows the comparison of cardiovascular variables across the groups at baseline, $4^{\text {th }}$ week, $8^{\text {th }}$ week and $12^{\text {th }}$ week post exercise intervention. It also shows the HbAlc values of subjects at baseline and at the end of the $12^{\text {th }}$ week. The RADBP and RRPP were significant at $4^{\text {th }}$ week, $8^{\text {th }}$ and $12^{\text {th }}$ week while the RASBP was significant at $12^{\text {th }}$ week only. There was significant difference in HbAlc across the groups. Table 5 shows the changes in $\mathrm{VO}_{2} \max , \mathrm{FVC}$ and $\mathrm{FEV}_{1}$ across the groups at baseline, $4^{\text {th }}$ week, $8^{\text {th }}$ week and $12^{\text {th }}$ week post exercise intervention. The $\mathrm{VO}_{2}$ max and $\mathrm{FEV}_{1}$ were significant at $4^{\text {th }}$ week, $8^{\text {th }}$ week and $12^{\text {th }}$ week, while the FVC was significant at $4^{\text {th }}$ week, $8^{\text {th }}$ week but not at $12^{\text {th }}$ week.

\begin{tabular}{|c|c|c|c|c|}
\hline & WBARE & NWBARE & CONTROL & $X^{2}, F$ and $p$ value \\
\hline \multicolumn{5}{|l|}{ Sex } \\
\hline Female & $12(60 \%)$ & $7(35 \%)$ & $9(45 \%)$ & \multirow{3}{*}{$X^{2}=2.55, p=0.28$} \\
\hline Male & $8(40 \%)$ & $13(65 \%)$ & $11(55 \%)$ & \\
\hline Total & $20(100 \%)$ & $20(100 \%)$ & $20(100 \%)$ & \\
\hline Age & $62.85 \pm 6.03$ & $61.40 \pm 8.20$ & $61.90 \pm 2.1$ & $F=0.30, p=0.74$ \\
\hline Duration of diabetes(years) & $5.90 \pm 3.88$ & $6.95 \pm 4.07$ & $4.70 \pm 4.75$ & $F=1.40, p=0.25$ \\
\hline Weight (kg) & $75.20 \pm 8.92$ & $77.900 \pm 11.57$ & $88.05 \pm 8.77$ & $F=2.12, p=0.13$ \\
\hline Height (m) & $1.63 \pm 0.06$ & $1.59 \pm 0.09$ & $1.63 \pm 0.05$ & $F=2.19, p=0.12$ \\
\hline
\end{tabular}

Table 1: Descriptive characteristics of the study groups.

\begin{tabular}{|c|c|c|c|c|c|c|}
\hline VARIABLES & BASELINE & END OF $4^{\text {TH }}$ WEEK & END OF $8^{\text {TH }}$ WEEK & END OF $12^{\text {TH }}$ WEEK & F value & $p$ value \\
\hline \multicolumn{7}{|l|}{ CARDIOVASCULAR } \\
\hline $\mathrm{RASBP}(\mathrm{mmHg})$ & $135.70 \pm 18.39$ & $127.15 \pm 13.31$ & $124.90 \pm 13.19^{\star \mathrm{b}}$ & $120.55 \pm 11.88^{\star b}$ & 3.91 & $0.01^{*}$ \\
\hline RADBP (mmHg) & $80.50 \pm 6.74$ & $75.45 \pm 6.68$ & $75.85 \pm 5.27^{\star \mathrm{b}}$ & $71.35 \pm 5.35^{* \mathrm{~b}}$ & 7.64 & $0.00^{*}$ \\
\hline RRPP (beats/min/mmHg) & $10570.10 \pm 1818.34$ & $9513.45 \pm 1379.44^{* \mathrm{~b}}$ & $9456.00 \pm 1728.71$ & $8228.00 \pm 929.74$ & 8.10 & $0.00^{*}$ \\
\hline \multicolumn{7}{|l|}{ PULMONARY } \\
\hline VO2max (kg/ml/min) & $21.32 \pm 5.33$ & $23.19 \pm 4.82$ & $26.05 \pm 4.58^{* \mathrm{~b}}$ & $28.64 \pm 4.88^{* \mathrm{~b}}$ & 8.58 & $0.00^{*}$ \\
\hline FVC (Litres) & $1.50 \pm 0.22$ & $2.06 \pm 0.49$ & $2.18 \pm 0.53^{\star \mathrm{b}}$ & $2.13 \pm 0.57^{\star \mathrm{b}}$ & 8.78 & $0.00^{*}$ \\
\hline FEV1 (Litres) & $1.42 \pm 0.27$ & $1.94 \pm 0.44$ & $2.14 \pm 0.54^{\star b}$ & $2.32 \pm 0.45^{\star b}$ & 15.89 & $0.00^{*}$ \\
\hline \multicolumn{7}{|l|}{ BIOCHEMICAL } \\
\hline $\mathrm{HbA} 1 \mathrm{C}(\%)$ & $7.38 \pm 1.23$ & & & $6.07 \pm 0.86$ & $t=15.28$ & $0.00^{*}$ \\
\hline
\end{tabular}

Key: RASBP $=$ Resting Arterial Systolic BP, RADBP= Resting Arterial Diastolic BP, RRPP = Resting rate pressure product, $\mathrm{VO} 2 \mathrm{max}=$ oxygen uptake, FVC= Forced vital capacity, FEV1= Forced Expiratory Volume in one second, HbA1c= Glycosylated haemoglobin, ${ }^{* b}=$ significantly different from baseline at $p<0.05$, ${ }^{*}=$ significant difference across the weeks

Table 2: Cardiopulmonary Variables and HbA1c values of Participants in WBARE Group.

\begin{tabular}{|c|c|c|c|c|c|c|}
\hline VARIABLES & BASELINE & END OF $4^{\text {TH }}$ WEEK & END OF $\mathbf{8}^{\mathrm{TH}}$ WEEK & END OF $12^{\text {TH }}$ WEEK & $F$ value & $p$ value \\
\hline \multicolumn{7}{|l|}{ CARDIOVASCULAR } \\
\hline RASBP $(\mathrm{mmHg})$ & $136.20 \pm 16.81$ & $135.00 \pm 14.40$ & $125.30 \pm 13.06^{* b}$ & $123.90 \pm 13.00^{\star b}$ & 3.94 & $0.01^{*}$ \\
\hline RADBP (mmHg) & $82.75 \pm 8.33$ & $80.75 \pm 5.84$ & $75.20 \pm 5.47^{\star \mathrm{b}}$ & $71.55 \pm 5.84^{* \mathrm{~b}}$ & 12.54 & $0.00^{*}$ \\
\hline RRPP (beat/min/mmHg) & $11307.75 \pm 2002.74$ & $10492.35 \pm 1540.40$ & $9791.05 \pm 1570.99^{* b}$ & $8979.90 \pm 1816.44^{* \mathrm{~b}}$ & 6.49 & $0.00^{*}$ \\
\hline \multicolumn{7}{|l|}{ PULMONARY } \\
\hline VO2max (kg/ml/min) & $21.55 \pm 2.44$ & $22.01 \pm 3.62$ & $27.35 \pm 3.76^{* \mathrm{~b}}$ & $28.02 \pm 4.17^{\star b}$ & 18.57 & $0.00^{*}$ \\
\hline FVC (litres) & $1.54 \pm 0.39$ & $1.55 \pm 0.39$ & $1.72 \pm 0.45$ & $1.86 \pm 0.52$ & 2.46 & 0.07 \\
\hline FEV1(litres) & $1.36 \pm 0.41$ & $1.46 \pm 0.43$ & $1.68 \pm 0.33^{\star b}$ & $1.77 \pm 0.39^{\star \mathrm{b}}$ & 4.71 & $0.00^{*}$ \\
\hline \multicolumn{7}{|l|}{ BIOCHEMICAL } \\
\hline $\mathrm{HbA} 1 \mathrm{C}(\%)$ & $6.97 \pm 0.90$ & & & $6.02 \pm 0.74^{\star b}$ & $t=13.32$ & $0.00^{*}$ \\
\hline
\end{tabular}

Key: RASBP $=$ Resting arterial systolic $\mathrm{BP}, \mathrm{RADBP}=$ Resting arterial diastolic $\mathrm{BP}, \mathrm{RRPP}=$ Resting rate pressure product, $\mathrm{VO} 2 \mathrm{max}=$ oxygen uptake, $\mathrm{FVC}=\mathrm{Forced}$ vital capacity, FEV1= Forced expiratory volume in one second, $\mathrm{HbA} 1 \mathrm{c}=$ Glycosylated haemoglobin, ${ }^{* b}=$ significantly different from baseline at $\mathrm{p}<0.05,{ }^{*}=$ significant difference across the week

Table 3: Cardiopulmonary Variables and HbA1c values of Participants in NWBARE Group. 
Citation: Osho OA, Akinbo S, Osinubi A, Olawale O (2011) Effect of Weight Bearing and Non-Weight Bearing Aerobics Combined with Resistance Exercises on the Cardiopulmonary Functions of Nigerians with Type 2 Diabetes Mellitus. J Diabetes Metab S10:001. doi:10.4172/21556156.S10-001

\begin{tabular}{|c|c|c|c|c|}
\hline & CARDIOVASCULAR VARIABLES & WBARE & NWBARE & CONTROL \\
\hline \multirow[t]{4}{*}{ BASELINE } & RASBP (mmHg) & $135.70 \pm 18.39$ & $136.20 \pm 16.81$ & $134.60 \pm 8.82$ \\
\hline & RADBP (mmHg) & $80.50 \pm 6.74$ & $82.75 \pm 8.33$ & $78.90 \pm 3.85$ \\
\hline & RRPP (beats/min.mmHg) & $10570.10 \pm 1818.34$ & $11307.75 \pm 2002.74$ & $11509.00 \pm 765.83$ \\
\hline & HbA1c & $7.38 \pm 1.23$ & $6.97 \pm 0.90$ & $6.95 \pm 1.34$ \\
\hline \multirow[t]{3}{*}{$4^{\text {TH }}$ WEEK } & $\operatorname{RASBP}(\mathrm{mmHg})$ & $127.15 \pm 13.31$ & $135.00 \pm 14.40^{\star a}$ & $125.80 \pm 12.43$ \\
\hline & $\mathrm{RADBP}(\mathrm{mmHg})$ & $75.45 \pm 6.68$ & $80.75 \pm 5.84$ & $77.50 \pm 7.13$ \\
\hline & RRPP(beats/min.mmHg) & $9513.45 \pm 1379.44^{\star a}$ & $10492.35 \pm 1540.40$ & $10833.60 \pm 1397.40$ \\
\hline \multirow[t]{3}{*}{$8^{\text {TH }}$ WEEK } & RASBP (mmHg) & $124.90 \pm 13.19$ & $125.30 \pm 13.06$ & $128.80 \pm 6.57$ \\
\hline & RADBP (mmHg) & $75.85 \pm 5.27^{\star a}$ & $75.20 \pm 5.47^{\star a}$ & $79.80 \pm 4.25$ \\
\hline & RRPP (beats/min.mmHg) & $9456.00 \pm 1728.71$ & $9791.05 \pm 1570.99^{* a}$ & $11745.50 \pm 488.36$ \\
\hline \multirow[t]{4}{*}{$12^{\text {TH }}$ WEEK } & $\operatorname{RASBP}(m m H g)$ & $120.55 \pm 11.88^{\star b}$ & $123.90 \pm 13.00^{* a^{*} b}$ & $130.90 \pm 12.14$ \\
\hline & RADBP (mmHg) & $71.35 \pm 5.35^{\star \mathrm{a}^{* b}}$ & $71.55 \pm 5.84^{* a t b}$ & $77.00 \pm 6.16$ \\
\hline & RRPP (beats/min.mmHg) & $8228.00 \pm 929.74^{* a^{* b}}$ & $8979.90 \pm 1816.44^{t b}$ & $11103.60 \pm 1784.09$ \\
\hline & HbA1c & $6.07 \pm 0.86^{\text {*a }{ }^{* b}}$ & $6.02 \pm 0.74^{\star a^{*} \mathrm{~b}}$ & $6.77 \pm 0.71$ \\
\hline
\end{tabular}

Key: $\mathrm{RASBP}=$ Resting arterial systolic $\mathrm{BP}, \mathrm{RADBP}=$ Resting arterial systolic $\mathrm{BP}, \mathrm{RRPP}=$ Resting rate pressure product, $\mathrm{HbA} 1 \mathrm{C}=$ glycosylated haemoglobin level, ${ }^{*}=$ significantly different from control at $p<0.05,{ }^{* b}=$ significantly different from baseline at $p<0.05$

Table 4: Cardiovascular Variables and HbA1c values of the Study Groups.

\begin{tabular}{|c|c|c|c|c|}
\hline & VARIABLES & WBARE & NWBARE & CONTROL \\
\hline \multirow[t]{3}{*}{ BASELINE) } & $\mathrm{VO}_{2} \max (\mathrm{kg} / \mathrm{ml} / \mathrm{min})$ & $21.32 \pm 5.33$ & $21.55 \pm 2.44$ & $21.43 \pm 5.27$ \\
\hline & FEV1 (Litre) & $1.42 \pm 0.27$ & $1.36 \pm 0.41$ & $1.39 \pm 0.56$ \\
\hline & FVC(Litre) & $1.50 \pm 0.22$ & $1.54 \pm 0.39$ & $1.81 \pm 0.82$ \\
\hline \multirow[t]{3}{*}{$\left(4^{\text {TH }}\right.$ WEEK) } & $\mathrm{VO}_{2} \max (\mathrm{kg} / \mathrm{ml} / \mathrm{min})$ & $23.19 \pm 4.82^{\star a}$ & $22.01 \pm 3.62^{\star a}$ & $18.07 \pm 2.41$ \\
\hline & FEV1(Litre) & $1.94 \pm 0.44^{\star a}$ & $1.46 \pm 0.43$ & $1.47 \pm 0.57$ \\
\hline & FVC(Litre) & $2.06 \pm 0.49^{* a}$ & $1.55 \pm 0.39$ & $1.80 \pm 0.77$ \\
\hline \multirow[t]{3}{*}{$\left(8^{\mathrm{TH}}\right.$ WEEK) } & $\mathrm{VO}_{2} \max (\mathrm{kg} / \mathrm{ml} / \mathrm{min})$ & $26.05 \pm 4.58^{\star a}$ & $27.35 \pm 3.76^{\star a}$ & $18.17 \pm 2.86$ \\
\hline & FEV1 (Litre) & $2.14 \pm 0.54^{\star a}$ & $1.68 \pm 0.33$ & $1.61 \pm 0.53$ \\
\hline & FVC(Litre) & $2.18 \pm 0.53^{\star a}$ & $1.72 \pm 0.45$ & $1.78 \pm 0.73$ \\
\hline \multirow[t]{3}{*}{$\left(12^{\mathrm{TH}} \mathrm{WK}\right)$} & $\mathrm{VO}_{2} \max (\mathrm{kg} / \mathrm{ml} / \mathrm{min})$ & $28.64 \pm 4.88^{* a+b}$ & $28.02 \pm 4.17^{* a+b}$ & $19.94 \pm 6.15$ \\
\hline & FEV1 (Litre) & $2.32 \pm 0.45^{\star \mathrm{a}^{* \mathrm{~b}}}$ & $1.77 \pm 0.39^{* a^{*} \mathrm{~b}}$ & $1.48 \pm 0.55$ \\
\hline & FVC (Litre) & $2.13 \pm 0.57^{* \mathrm{~b}}$ & $1.86 \pm 0.52$ & $2.08 \pm 0.68$ \\
\hline
\end{tabular}

Key: $\mathrm{VO}_{2}$ max $=$ oxygen uptake, $\mathrm{FVC}=$ Forced vital capacity, FEV1= Forced expiratory volume in one second, ${ }^{\star a}=$ significantly different from control at $\mathrm{p}<0.05$, ${ }^{* \mathrm{~b}}=$ significantly different from baseline at $p<0.05$

Table 5: Pulmonary Variables of Study Groups.

The post hoc analysis results of the cardiopulmonary variables which were significant across the groups were also reported in Table 4 and 5. Comparison between WBARE group and control group shows no significant difference in RASBP while significant difference was recorded when NWBARE group was compared with control group at $4^{\text {th }}$ and $12^{\text {th }}$ week.

Significant difference in RADBP was recorded at $8^{\text {th }}$ and $12^{\text {th }}$ week when WBARE group was compared with control group and when NWBARE group and control group were also compared. RRPP when compared between WBARE and control group shows significant difference at $4^{\text {th }}$, and $12^{\text {th }}$ week while significant difference was recorded at $8^{\text {th }}$ week only between NWBARE and the control group.

Comparison between WBARE group and control group and between NWBARE group and control group shows significant difference in $\mathrm{VO}_{2}$ max at $4^{\text {th }} 8^{\text {th }}$ and $12^{\text {th }}$ week.

FVC was significant at $4^{\text {th }}$ and $8^{\text {th }}$ week when WBARE group and control group were compared while comparison between NWBARE group and control group shows no significant difference. $\mathrm{FEV}_{1}$ recorded significant difference at $4^{\text {th }}, 8^{\text {th }}$ and $12^{\text {th }}$ week when NWBARE group and control groups were compared while it was significant at $12^{\text {th }}$ week only when NWBARE group and control group were compared.

\section{Discussion}

This study compared the effect of weight bearing aerobic exercise on treadmill and non-weight bearing aerobic exercise on bicycle ergometer when either is combined with resistance exercise on the selected cardiopulmonary parameters of Nigerian adults with T2DM. It also assessed changes in these parameters at specified duration in the intervention period. The principal findings suggested that WBARE and NWBARE significantly improved cardiopulmonary parameters when compared with the control group. Significant improvement in some cardiopulmonary parameters (RRPP, VO2max and FEV1) occurred as early as four weeks post intervention. The current findings also suggested that WBARE is more effective in improving lung volumes; FEV1 and FVC than NWBARE. The findings in this study are in support of the report of previous studies who reported significant improvement in cardiopulmonary functions in T2DM patients following exercise interventions [34-37]. However, it is contrary to some reports in previous studies who reported no improvement in some pulmonary functions $[37,38]$.

Studies have established that exercise must be consistent and continuous for therapeutic effect to occur $[28,35]$. The result of this study showing improvement in cardiopulmonary function as early as $4^{\text {th }}$ week as recorded in the exercise groups suggested the therapeutic benefit that these modes of exercises may have on the physiological 
Citation: Osho OA, Akinbo S, Osinubi A, Olawale O (2011) Effect of Weight Bearing and Non-Weight Bearing Aerobics Combined with Resistance Exercises on the Cardiopulmonary Functions of Nigerians with Type 2 Diabetes Mellitus. J Diabetes Metab S10:001. doi:10.4172/21556156.S10-001

Page 6 of 7

and biochemical processes of the body of the studied DM patients. During exercise, skeletal muscle disposition of glucose produced and the untoward effect on the overall glucose control might have been responsible for the early significant improvement observed in parameters [39]. Both aerobics and resistance exercises play major role in preserving musculoskeletal function and independence [27]. Resistance exercises have been shown to favourably influence several metabolic and cardiovascular disease (CVD) risk factors that were traditionally thought to be exclusively associated with aerobic exercise [28]. Findings from previous studies have supported resistance exercises as being comparable to aerobic exercises in ameliorating CVD risk factors for more than a decade now [28]. A meta-analysis of randomized controlled trials also concluded that progressive resistance exercise is efficacious for reducing resting systolic and diastolic blood pressure in adults [35]. Although the authors admitted that reductions in blood pressure are modest, this study further effectively disputes the myth that resistance exercises are a detriment to blood pressure control. In addition, a combination of the therapeutic effect of both aerobic and resistance exercise might have produced a doubling therapeutic benefit which could have brought above the early improvement noted.

The improvement observed in the cardiopulmonary functions $\mathrm{FEV}_{1}, \mathrm{FVC}$ and $\mathrm{VO}_{2}$ max when across group comparison was done in this study may be attributed to the improvement in glucose metabolism which has been reported to occur acutely and immediately after exercise thus producing its effect even till 48 hour post exercise session $[8,9]$. The resultant effect of this is an improved glucose control as consistent exercise sessions continue. In addition, since the subjects in this study performed combined aerobic and resistance exercises thrice per week for twelve week (three months), this might have enabled adequate glucose control ( $\mathrm{HbA1c}$ ) which usually is a measure estimated within three month. Reduced lung volumes and airflow limitation has been reported to be chronic complications of T2DM. The severity of this decrease has been reported to relate to glycaemic exposure [9]. Poor glucose control has been links to microvascular complications and reduced ventilatory function of the lungs. Airflow limitation is a predictor of death in T2DM after adjusting for other recognized risk factors [9].

The greater improvement recorded in the pulmonary parameters $\left(\mathrm{FEV}_{1}\right.$ and $\left.\mathrm{FVC}\right)$ of the subjects in WBARE group in this study may be attributed to the fact that during whole body aerobic exercise which brought majority of the skeletal muscles into action such as treadmill walking, whole-body oxygen consumption increases by as much as 20 -fold and even greater increases occur in the working muscles with additional resistance exercise [36]. To meet its energy needs under these circumstances, skeletal muscle uses, at a greatly increased rate, its own stores of glycogen and triglycerides, as well as free fatty acids (FFAs) derived from the breakdown of adipose tissue triglycerides and glucose released from the liver leading to decreased blood glucose level [38]. With improved glucose control, inflammation of lung tissue and microvascular complications is better averted. The result is thus an improved lung function which might have been observed from the increased $\mathrm{FEV}_{1}, \mathrm{FVC}$ and $\mathrm{VO}_{2}$ max values as predominantly recorded in the subjects in WBARE group.

Improvement in cardio-respiratory function had been reported not to result from changes in the lung's ability to expand [37]. In general, individuals with T2DM who perform aerobic exercise regularly do not substantially change measures of pulmonary function such as the amount of air able to be blown out after taking the largest breath possible FVC [36]. This may explain the insignificant FVC values reported at $12^{\text {th }}$ week post intervention in the across group comparison despite significant improvement in $\mathrm{FEV}_{1}$ in both exercise groups all through the assessments done during the intervention period. In addition, increase expiratory muscle strength has been linked to increase $\mathrm{FEV}_{1}$ and FVC [22,38]. However, assessment of strength of abdominal muscles which were the major expiratory muscles exercised during the resistance exercises in this study was not done being outside the scope of this study and thus we could not accurately ascertain this report.

This study suggested that individuals with T2DM who undergo weight bearing aerobic exercise on treadmill combined with resistance exercise and those who undergo non-weight bearing exercise on bicycle ergometer may not have a lesser or superior benefit over each other in terms of positive responses in their cardiorespiratory functions and glucose control (HbA1C). However better pulmonary functions; FVC and FEV1 may be recorded in those who undergo weight bearing aerobic exercise on treadmill combined with resistance exercise. Furthermore, since both WBARE and NWBARE have beneficial effects, the choice of either should ultimately depend on the superior judgment of the clinicians; it should also depend on the outcome measures which the clinicians are aiming at improving on. In the absence of significant reduction in the pulmonary variables, NWBARE will be suggested especially if there are contradicting foot pathologies which may be aggravated by WBARE, otherwise WBAE will be more beneficial in the absence of foot pathologies. In addition, therapeutic effect of moderate intensity combined aerobic and resistance exercise may occur as early as four weeks in majority of the cardiopulmonary parameters post exercise intervention. Assessment of patients' response in terms of therapeutic effect and improvement on the cardiopulmonary functions, following prescription of combined aerobic and resistance exercises should thus commence as early as the fourth week post intervention in people with T2DM in order to follow the trend of improvement.

\section{Acknowledgements}

This study was partly funded by a grant from Doctoral Assistance Grant of the University of Lagos, Nigeria. We thank Dr. Anthonia Ogbera, and $\mathrm{Dr}$. O. A Fasanmade of the Endocrinonogy unit, Department of Medicine of LUTH and LASUTH, Lagos, Nigeria for support on patient recruitment and screening. Dr. Adegoke of Chemical Patholgy Department LUTH for analyzing the blood samples for $\mathrm{HbA} 1 \mathrm{c}$ and all the patients who volunteered to participate in this study.

\section{References}

1. Zi mmet Pz, Mccarty DJ, De couten MP (1997) The global epidemiology of noninsulin dependent diabetes mellitus and the metabolic syndrome. J Diabetes Complications 11: 60-68

2. Abubakaria AR, Bhopalb RS (2008) Systematic review on the prevalence of diabetes, overweight/obesity and physical inactivity in Ghanaians and Nigerians. Public Health 122: 173-182.

3. Nyenwe EA, Odia OJ, Ihekwaba AE, Ojule A, Babatunde S (2003) Type 2 diabetes in adult Nigerians: a study of its prevalence and risk factors in Port Harcourt, Nigeria. Diabetes Research and Clinical Practice 62: 177-185

4. Familoni OB, Olatunde O, Raimi TH (2008) The relationship between QT interval and Cardiac Autonomic Neuropathy in Nigerian Patients with Type 2 Diabetes Mellitus. Nigeria Medical Practioner 53: 48-51.

5. National Institute of Health Publication (2011) National Diabetes Statistics No 11-3892.

6. Bello-Sani F, Anumah FEO (2009) Electrocardiographic abnormalities in persons with type 2 diabetes in Kaduna, Northern Nigeria. Int $\mathrm{J}$ Diabetes \& Metabolism 17: 99-103

7. Ozoh OB, Okubabejo NU, Bandele EO, Chukwu CC (2010) Ventiliatory function in Nigerians with type 2 diabetes. African Journal of Respiratory Medicine on line: 18-22. 
Citation: Osho OA, Akinbo S, Osinubi A, Olawale O (2011) Effect of Weight Bearing and Non-Weight Bearing Aerobics Combined with Resistance Exercises on the Cardiopulmonary Functions of Nigerians with Type 2 Diabetes Mellitus. J Diabetes Metab S10:001. doi:10.4172/21556156.S10-001

8. Kaminski DM, D'Agord Schaan BD, da Silva AMV, Soares PP, Plentz RDM, et al. (2010) Inspiratory muscle weakness is associated with autonomic cardiovascular dysfunction in patients with type 2 diabetes mellitus. Clinical Autonomic Research 21: 29-35.

9. Davis WA, Knuiman M, Kendall P, Grange V, Davis TME (2004) Glycemic exposure is associated with reduced pulmonary function in type 2 diabetes: the Fremantle Diabetes Study. Diabetes Care 27: 752-757.

10. Diloreto C, Faneli C, Lucidi P (2005) Make your diabetic patient walk: Long term impact of different amounts of physical activity on type 2 diabetes. Diabetes Care 28: 1295-1302.

11. Arora E, Shenoy S, Sandhu JS (2009) Effects of resistance training on metabolic profile of adults with type 2 diabetes. Indian J Med Res 129: 515-519.

12. Kalra S, Kalra B, Kumar N (2007) Prevention and management of diabetes: the role of the physiotherapy. Diabetes Voice 52: 12-15.

13. Laaksonen DE (2003) Role of physical exercise, fitness and aerobics training in type 1 diabetic and healthy men in relation to the lipid profile, lipid peroxidation and the metabolic syndrome. Journal of Sport Science and Medicine 2: 1-65.

14. Fletcher B, Berra K, Ades P, Burke LE, Durstine JL, et al. (2005) Managing Abnormal Blood Lipids. Circulation 112: 3184-3209.

15. Osho OA, Abidoye RO, Owoeye OB, Akinfeleye AM, Akinbo SR (2011) Physical Activity level, Nutritional intake, Functional status and Quality of Life of Geriatric Individuals in Lagos, South West, Nigeria: A cross Sectional Survey. Nig Q J Hosp Med 21: 9-15.

16. Akinbo SRA (2008) Physiotherapy in healing and management. Nigerian Journal of Medical Rehabilitation 13: iii - vii.

17. Huo M, Maruyama H, Liu H (2006) Optimal pedaling rate in bicycle ergometer exercise determined by probe reaction time. Percept Mot Skills 103: 703-708.

18. Marwick TH, Hordern MD, Miller T, Chyun DA, Bertoni AG, et al. (2009) Exercise Training for Type 2 Diabetes Mellitus. Impact on Cardiovascular Risk: A Scientific Statement From the American Heart Association. Circulation 119 3244-3262.

19. Timothy R, Connell MC (2003) The cardio-respiratory fitness evaluation of apparently healthy people by means of a sub maximal stress test COSMED (pulmonary function equipment). Cardiopulmonary news 23: 1-3.

20. Ramsbottom R, Kinch RF, Morris MG, Dennis AM (2007) Practical application of fundamental concepts in exercise physiology. Advan Physiol Edu 31: $347-$ 351

21. American College of Sports Medicine and the American Diabetes Association (2010) Joint Position Statement. Exercise and Type 2 Diabetes. Medicine \& Science in Sports \& Exercise 42: 2282-2303.

22. Ferdowsi MH, Abdulamir S, Rohollah V, Gholamie A (2011) The effect of eight week aerobic exercise on airway trachea indexes (FEV1, FVC, FEV1.FVC \& FEF25-75) and $\mathrm{VO}_{2}$ max level in overweighed male students of Ahvaz Payam Noor University. Procedia - Social and Behavioural Sciences 15: 2848-2852.

23. Tapolski TD, LoGerfo J, Patrick DL, Williams B, Walwick J, et al. (2006) The Rapid Assessment of Physical Activities Among Older Adullts. Prev chrnic Dis

24. Jones AM, Doust JH (1996) A $1 \%$ treadmill grade most accurately reflects the energetic cost of outdoor running. J Sports Sci 14: 321-327.

25. Adeniyi AF, Sanya AO, Fasanmade AA, Tijani B, Uloko AE (2007) Association between pulse index and metabolic syndrome in individuals with Type 2 Diabetes mellitus: outcome of a twelve- weeks therapeutic exercise programme. Nigerian Journal of Medical Rehabilitation 12: 8-12.

26. Travlos AK (2009) The immediate aftereffects of one hour submaximal steady state aerobic exercise of high- and low-fit individuals in a random number generation test. Journal biology and exercise 5: 41-50.

27. Sigal RJ, Glen PK, Normand GB, Wells GA, Prud'homme D, et al. (2007) Effects of Aerobic Training, Resistance Training, or Both on Glycemic Control in Type 2 Diabetes. Ann Intern Med 147: 357-369.
28. Kluding PM, Singh R, Goetz J, Rucker J, Bracciano S, et al. (2010) Feasibility and Effectiveness of a Pilot Health Promotion Program for Adults With Type 2 Diabetes, Lessons Learned. The Diabetes Educator 36: 595-602.

29. Hermida RC, Fernández JR, Ayala DE, Mojón A, Alonso I, et al. (2001) Circadian rhythm of double (rate-pressure) product in healthy normotensive young subjects. Chronobiology International 18: 475-489.

30. Kilne GM, Porcar JP, Hintermeister R, Freedson PS, Ward A, et al. (1987) Estimation of $\mathrm{VO} 2 \mathrm{max}$ from a one mile track walk, gender, age and body weight. Med Sci Sport Exerc 19: 7-15.

31. O'Dea K, Walker K, Simmons D, Garry Egger G, Mann J (2001) National Evidence Based Guidelines for the Management of Type 2 Diabetes Mellitus Part 2. Primary Prevention of Type 2 Diabetes. The Australian Centre for Diabetes Strategies Prince of Wales Hospital, Sydney for the Diabetes Australia Guideline Development Consortium. Approved by the National Health and Medical Research Council.

32. Tella BA, Sanni KA (2005) Effect of acute exercises on pulmonary function in Non-Insulin dependent Diabetes mellitus (NIDDM) subjects. Nigerian Journal of Medical Rehabilitation 10: 30-34

33. Shenoy S, Ekta Arora E, Jaspal S (2009) Effects of progressive resistance training and aerobic exercises on type 2 diabetics in Indian population. Int $J$ Diabetes \& Metabolism 17: 27-30.

34. American Thoracic Society (1995) Standardization of spirometry, 1994 update. Am J Respir Crit Care Med 152: 1107-1136

35. Gordon LA, Morrison EY, McGrowder DA, Young R, Fraser PT, et al. (2008) Effect of exercise therapy on lipid profile and oxidative stress indicators in patients with type 2 diabetes. Biomedical Central Complementary and Alternative Medicine 8: 1-6

36. Baldi JC, Cassuto NA, Foxx-Lupo WT, Wheatley CM, Snyder EM (2010) Glycemic Status Affects Cardiopulmonary Exercise Response in Athletes with Type I Diabetes. Medicine and Science in Sports and Exercise 42: 1454-1459.

37. Jones RL, Magdalene M, Nzekwu U (2006) The effects of body mass index on lung volumes. Chest 130: 827-833.

38. American Diabetes Association (2004) Tests of Glycaemia in Diabetes. Diabetes Care 27: 91-93.

39. Sigal RJ, Glen P. Kenny GP, Wasserman DH, Sceppa CC (2004) Physical Activity/exercise and type 2 Diabetes. Diabetes Care 27: 2518-2539. 